\title{
Usefulness of TAS-102 as Third-line Chemotherapy for Metastatic Colorectal Cancer
}

\author{
HIDEJIRO KAWAHARA ${ }^{1}$, TAKASHI MOURI ${ }^{1}$, KOTA ISHIDA ${ }^{1}$, NORI MATSUMOTO ${ }^{1}$, \\ TADASHI AKIBA ${ }^{1}$ and KATSUHIKO YANAGA ${ }^{2}$ \\ ${ }^{1}$ Department of Surgery, Kashiwa Hospital, Jikei University School of Medicine, Chiba, Japan; \\ ${ }^{2}$ Department of Surgery, Jikei University School of Medicine, Tokyo, Japan
}

\begin{abstract}
Background/Aim: The feasibility and oncological outcomes of treatment with TAS-102, that is recommended as third-line chemotherapy for patients with metastatic colorectal cancer $(m C R C)$, remain unknown. Patients and Methods: Between 2013 and 2015, seven patients (five males, two females) with $\mathrm{mCRC}$ who were administered TAS102 as third-line chemotherapy at our Institution were retrospectively studied. During the same period, seven patients with $\mathrm{mCRC}$ with Kirsten rat sarcoma viral oncogene homolog (KRAS) wild-type primary lesions who were administered irinotecan with panitumumab comprised the control group. Results: The duration of third-line chemotherapy in the TAS-102 group was 217.0 (range $=136$ 337) days compared to 226.9 (range $=122-335$ ) days in the control group, with no significant difference in the duration of administration between the two groups. No significant difference in overall survival was identified between the two groups No serious adverse effects were encountered in either group. Conclusion: TAS-102 may be suitable as third-line chemotherapy for patients with $\mathrm{mCRC}$.
\end{abstract}

In Japan, first-, second-, third-, and fourth-line chemotherapy treatments for patients with metastatic colorectal cancer (mCRC) are administered according to the recommendations of the Japanese Society for Cancer of the Colon and Rectum Guidelines $(1,2)$. TAS-102 (Taiho Pharmaceutical Co. Ltd, Tokyo, Japan) is a novel oral antitumor agent recommended as third- or fourth-line chemotherapy in the 2016 guidelines (2). However, the feasibility and oncological outcomes of treatment with

Correspondence to: Hidejiro Kawahara, MD, Ph.D., Department of Surgery, Kashiwa Hospital, Jikei University School of Medicine, 163-1 Kashiwashita, Kashiwashi, Chiba 277-8567, Japan. Tel: +81 471641111 Ext.3421, Fax: +81 471633488, e-mail: kawahide@ jikei.ac.jp

Key Words: TAS-102, metastatic colorectal cancer, third-line chemotherapy.
TAS-102 compared with those of other third-line regimens remain unknown. We retrospectively evaluated the usefulness of TAS-102 as third-line chemotherapy.

\section{Patients and Methods}

Patients. The Ethics Committee for Biomedical Research of the Jikei Institutional Review Board approved the protocol [29-041 (8657)], and all patients or their family members provided their written informed consent to participation. Between 2013 and 2015, seven patients with mCRC who received TAS-102 as third-line chemotherapy were enrolled in the study. During the same period, seven patients with unresectable mCRC who were administered irinotecan with panitumumab comprised the control group. These 14 patients were given oxaliplatin with oral S-1 (tegafur, gimeracil, oteracil potassium) (SOX) as first-line chemotherapy, followed by the administration of irinotecan with oral S-1 (IRIS) as second-line chemotherapy. Patients were only included in this study if they demonstrated adequate organ function [leukocytes: 4,000 to $<12,000 / \mathrm{mm}^{3}$; thrombocytes, $\geq 100,000 / \mathrm{mm}^{3}$; total serum bilirubin, $\leq 1.5 \mathrm{mg} / \mathrm{dl}$; aspartate aminotransferase (AST) and alanine aminotransferase (ALT), <100 IU/l; and creatinine, $\leq 1.5 \mathrm{mg} / \mathrm{dl}]$. Patients with a history of drug hypersensitivity or serious surgical and non-surgical complications were excluded.

Treatment schedule. Physical examinations, routine blood analyses, and serum carcinoembryonic antigen (CEA) measurements were performed every month before chemotherapy. Computed tomography (CT) was performed every 2 months or when a patient's serum CEA value on the treatment day was higher than it had been before the initial chemotherapy. The response of measurable and accessible disease sites was evaluated according to the Response Evaluation Criteria in Solid Tumors (RECIST) (3).

SOX (4) was employed as the first-line treatment. Oxaliplatin at $130 \mathrm{mg} / \mathrm{m}^{2}$ was administered on the first day, followed by 14-day administration and 6-day withdrawal of oral S-1 (Taiho Pharmaceutical, Tokyo, Japan) at $80 \mathrm{mg}$ or $100 \mathrm{mg}$ per day according to the patient's body surface area (BSA), with $80 \mathrm{mg}$ /day administered to those patients with $\mathrm{BSA}<1.5 \mathrm{~m}^{2}$ and $100 \mathrm{mg} /$ day administered to those patients with BSA>1.5 $\mathrm{m}^{2}$. S-1 was administered orally twice daily after meals.

Irinotean with oral S-1 (IRIS) (5) was employed as the second-line treatment. Irinotecan at $120 \mathrm{mg} / \mathrm{m}^{2}$ was administered on the first day, followed by 14-day administration and 6-day withdrawal of oral S-1 
(Taiho Pharmaceutical, Tokyo, Japan) at $80 \mathrm{mg}$ or $100 \mathrm{mg}$ per day according to the patient's body surface area (BSA), with $80 \mathrm{mg} /$ day administered to those patients with $\mathrm{BSA}<1.5 \mathrm{~m}^{2}$ and $100 \mathrm{mg} / \mathrm{day}$ administered to those patients with $\mathrm{BSA}>1.5 \mathrm{~m}^{2}$. $\mathrm{S}-1$ was administered orally twice daily after meals.

Two regimens, TAS-102 or irinotecan with panitumumab therapy, were employed as the third-line treatment. TAS- 102 at $35 \mathrm{mg} / \mathrm{m}^{2}$ was administered twice daily, after morning and evening meals, 5 days a week for 2 weeks, followed by a 14-day rest period, thus completing one treatment cycle. The regimen was repeated every 4 weeks.

Irinotecan with panitumumab therapy was selected as the thirdline treatment for those with Kirsten rat sarcoma viral oncogene homolog (KRAS) wild-type colorectal adenocarcinoma. Irinotecan at $120 \mathrm{mg} / \mathrm{m}^{2}$ and panitumumab at $6 \mathrm{mg} / \mathrm{kg}$ were administered on the first day, followed by a 13-day rest period.

Adverse events were classified and graded according to the National Cancer Institute Common Terminology Criteria for Adverse Events, version 4.03 (6).

Statistical analysis. Continuous variables are expressed as the mean and range. The Wilcoxon rank-sum test was used for the comparison of continuous variables, and the chi-square test was used for the comparison of categorical data. Postoperative relapse-free survival rates were examined by the Kaplan-Meier method and log-rank analysis. A $p$-value of less than 0.05 indicated significance. All data were analyzed with IBM SPSS Statistics, version 22.0 (IBM Japan, Ltd, Tokyo, Japan)

\section{Results}

Patient characteristics. No significant differences in age, gender, primary site of disease, recurrent site of disease, or the duration of each chemotherapy treatment were identified between the two treatment groups (Table I).

Comparison of survival after second-line chemotherapy between the two groups. The survival time after second-line chemotherapy was 271.0 (136-337) days in the TAS-102 group and 226.9 (122-335) days in the combination group. No significant difference was identified between the two groups (Figure 1).

Comparison of overall survival between two groups. Overall survival was 852.3 (681-964) days in the TAS-102 group and 840.1 (722-954) days in the combination group. No significant difference was identified between the two groups (Figure 2).

Adverse effects after starting the two chemotherapy regimens. No serious adverse effects greater than grade 2 were encountered in either group.

\section{Discussion}

The infusion of fluorouracil and leucovorin combined with either oxaliplatin (FOLFOX) or irinotecan (FOLFIRI), as well as oral drugs combined with either oxaliplatin [SOX (4), XELOX (7)] or irinotecan [IRIS (5), XELIRI (8)], have been
Table I. Clinicopathological characteristics of patients treated with TAS102 and the control group treated with the combination of irinotecan with panitumumab.

\begin{tabular}{|c|c|c|c|}
\hline Variable & $\begin{array}{l}\text { TAS-102 } \\
(\mathrm{n}=7)\end{array}$ & $\begin{array}{l}\text { Control } \\
(n=7)\end{array}$ & $p$-Value \\
\hline \multicolumn{3}{|l|}{ Gender, n (\%) } & 0.592 \\
\hline Male & $5(71)$ & $5(71)$ & 1.000 \\
\hline Female & $2(29)$ & $2(29)$ & \\
\hline \multicolumn{4}{|l|}{$\begin{array}{l}\text { Primary site of } \\
\text { disease, } \mathrm{n}(\%)\end{array}$} \\
\hline Colon & $4(58)$ & $4(58)$ & 1.000 \\
\hline Rectum & $3(42)$ & $3(42)$ & \\
\hline \multicolumn{4}{|l|}{ Recurrent site, n (\%) } \\
\hline Liver & $2(29)$ & $1(14)$ & 0.766 \\
\hline Lung & $2(29)$ & $3(43)$ & \\
\hline Peritoneum & $3(42)$ & $3(43)$ & \\
\hline \multicolumn{4}{|l|}{$\begin{array}{l}\text { Median duration of } \\
\text { therapy (range), days }\end{array}$} \\
\hline First line & $224.0(203-245)$ & $220.4(202-234)$ & 0.684 \\
\hline Second line & $282.1(178-365)$ & $278.6(233-304)$ & 0.565 \\
\hline Third line & $217.9(136-337)$ & $226.9(122-335)$ & 0.995 \\
\hline
\end{tabular}

widely used as first-line or second-line chemotherapy for mCRC. There is no effective third-line chemotherapy regimen, although irinotecan with panitumumab (9) was recommended as third-line chemotherapy in the 2014 guidelines (1). TAS102 is a novel oral antitumor agent recommended as third-line chemotherapy in the 2016 guidelines (2). TAS-102 is a combination of an antineoplastic thymidine-based nucleoside analog, trifluridine, and a thymidine phosphorylase inhibitor, tipiracil hydrochloride, at a molar ratio of 1:0.5 (weight ratio, $1: 0.471)(10-12)$. Based on the results of a randomized phase II trial (13), TAS-102 was approved for the first time in Japan in March 2014 by the Pharmaceutical and Medical Devices Agency, with an initial indication being in patients with mCRC that is refractory to all standard therapies defined in the 2014 Japanese colorectal cancer treatment guidelines (1). A large-scale global phase III trial (RECOURSE trial) to evaluate the efficacy and safety of TAS-102 showed significant improvement in overall and progression-free survival in patients administered TAS-102 compared to those administered a placebo (14). Accordingly, the recommendation of TAS-102 as third- or fourth-line chemotherapy was revised to include treatment for patients with mCRC in the 2016 guidelines (2). However, the feasibility and oncological outcomes of using TAS-102 as third-line chemotherapy compared with the those using other third-line regimens are unknown. We retrospectively evaluated the usefulness of TAS102 as third-line chemotherapy.

In this study, seven patients with mCRC with KRAS wildtype primary lesions who were administered irinotecan with 


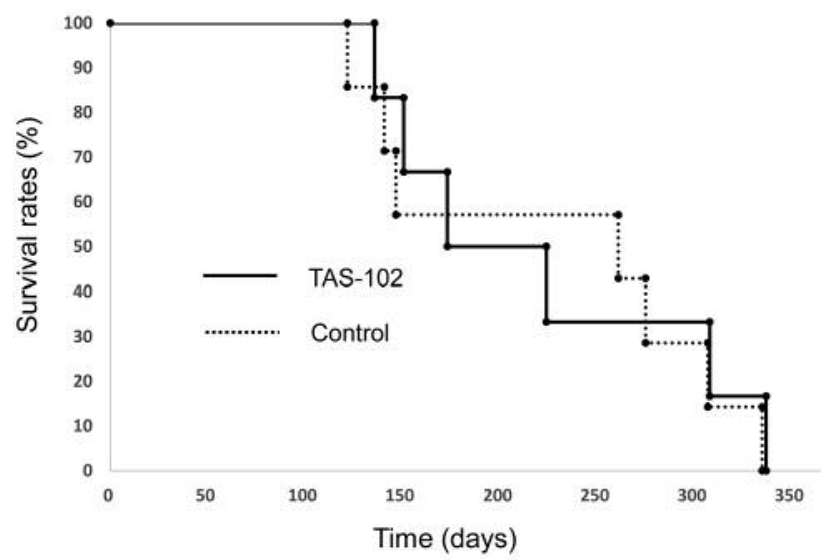

Figure 1. Comparison of survival after second-line chemotherapy between patients subsequently treated with TAS-102 and the control group treated with the combination of irinotecan with panitumumab; no significant difference in survival was identified between groups.

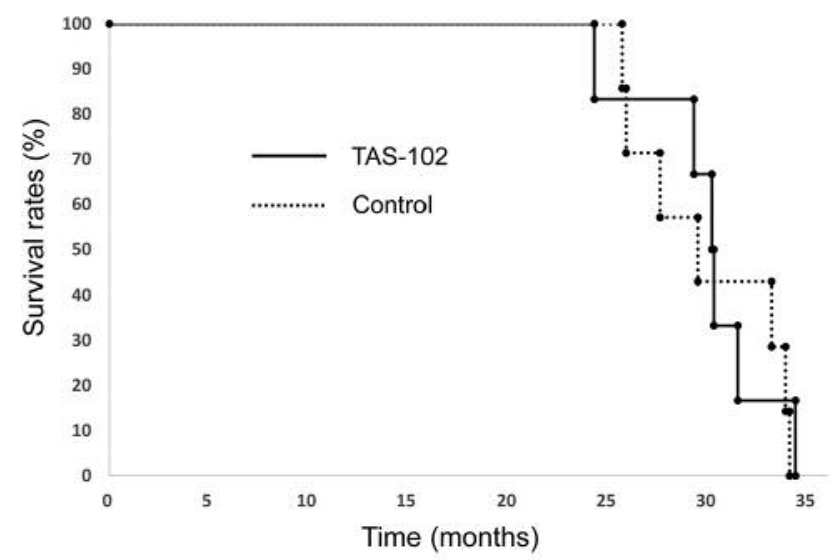

Figure 2. Comparison of overall survival between patients treated with TAS-102 and the control group treated with the combination of irinotecan with panitumumab; no significant difference in survival was identified between groups. panitumumab comprised the control group. This combination has been recommended for more than 5 years as third-line chemotherapy for patients with mCRC whose primary lesions are KRAS wild-type (1). No significant difference was identified between the two groups in terms of survival after second-line chemotherapy. Therefore, the feasibility and oncological outcomes of TAS-102, an oral antitumor agent, seem to be equivalent to those of irinotecan with panitumumab, which is infused chemotherapy.

The toxic effects of TAS-102 were generally mild, and the agent was well tolerated (15). Myelosuppression was the main adverse event caused by TAS-102; however, it was manageable with dose reductions or temporary interruptions in treatment. Non-hematological adverse events, such as peripheral neuropathy, hand-foot syndrome, fatigue, and diarrhea, were uncommon (16). No serious adverse events greater than grade 2 were encountered in our study.

In conclusion, TAS-102 may be suitable as third-line chemotherapy that is comparable to irinotecan with panitumumab for patients with mCRC; however, a largescale prospective study is needed.

\section{Conflict of Interest}

The Authors declare that they have no conflict of interest in regard to this study.

\section{References}

1 Watanabe T, Itabashi M, Shimada Y, Tanaka S, Ito Y, Ajioka Y, Hamaguchi T, Hyodo I, Igarashi M, Ishida H, Ishihara S, Ishiguro M, Kanemitsu Y, Kokudo N, Muro K, Ochiai A, Oguchi M, Ohkura Y, Saito Y, Sakai Y, Ueno H, Yoshino T, Boku N, Fujimori T, Koinuma N, Morita T, Nishimura G, Sakata Y,
Takahashi K, Tsuruta O, Yamaguchi T, Yoshida M, Yamaguchi N, Kotake K, Sugihara K; Japanese Society for Cancer of the Colon and Rectum. Japanese Society for Cancer of the Colon and Rectum (JSCCR) Guidelines 2014 for treatment of colorectal cancer. Int J Clin Oncol 20: 207-239, 2015.

2 Watanabe T, Muro K, Ajioka Y, Hashiguchi Y, Ito Y, Saito Y, Hamaguchi T, Ishida $H$, Ishiguro M, Ishihara S, Kanemitsu $Y$, Kawano H, Kinugasa Y, Kokudo N, Murofushi K, Nakajima T, Oka S, Sakai Y, Tsuji A, Uehara K, Ueno H, Yamazaki K, Yoshida M, Yoshino T, Boku N, Fujimori T, Itabashi M, Koinuma N, Morita T, Nishimura G, Sakata Y, Shimada Y, Takahashi K, Tanaka S, Tsuruta O, Yamaguchi T, Yamaguchi N, Tanaka T, Kotake K, Sugihara K; Japanese Society for Cancer of the Colon and Rectum. Japanese Society for Cancer of the Colon and Rectum (JSCCR) guidelines 2016 for the treatment of colorectal cancer. Int J Clin Oncol 23: 1-34, 2018.

3 Therasse P, Arbuck SG, Eisenhauer EA, Wanders J, Kaplan RS, Rubinstein L, Verweij J, Van Glabbeke M, van Oosterom AT, Christian MC and Gwyther SG: New guidelines to evaluate the response to treatment in solid tumors. European Organization for Research and Treatment of Cancer, National Cancer Institute of the United States, National Cancer Institute of Canada. J Natl Cancer Inst 92: 205-216, 2000.

4 Yamada Y, Tahara M, Miya T, Satoh T, Shirao K, Shimada Y, Ohtsu A, Sasaki Y and Tanigawara Y: Phase I/II study of oxaliplatin with oral S-1 as first-line therapy for patients with metastatic colorectal cancer. Br J Cancer 98: 1034-1038, 2008.

5 Choi YH, Kim TW, Kim KP, Lee SS, Hong YS, Ryu MH, Lee JL, Chang HM, Ryoo BY, Kim HS, Shin JG and Kang YK: A phase II study of clinical outcomes of 3-week cycles of irinotecan and $\mathrm{S}-1$ in patients with previously untreated metastatic colorectal cancer: influence of the UGT1A1 and CYP2A6 polymorphisms on clinical activity. Oncology 82: 290-297, 2012.

6 Department of Health and Human Services, National Institutes of Health, National Cancer Institute. Common terminology criteria for adverse events (CTCAE) v4.03. 2010 (http://evs. nci.nih.gov/ ftp1/CTCAE/CTCAE_4.03_2010-06-14_QuickReference_5x7.pdf). 
7 Twelves CJ, Butts CA, Cassidy J, Conroy T, Braud Fd, DiazRubio E and Tabernero JM, Schoffski P, Figer A, Brunet R, Grossmann J, Sobrero AF, Van Cutsem EJ: Capecitabine/ oxaliplatin, a safe and active first-line regimen for older patients with metastatic colorectal cancer: Post hoc analysis of a large phase II study. Clin Colorectal Cancer 5: 101-107, 2005.

8 Patt YZ, Lee FC, Liebmann JE, Diamandidis D, Eckhardt SG, Javle M, Justice GR, Keiser W, Salvatore JR, Bexon A and Lin E: Capecitabine plus 3-weekly irinotecan (XELIRI regimen) as first-line chemotherapy for metastatic colorectal cancer: phase II trial results. Am J Clin Oncol 30: 350-357, 2007.

9 André $\mathrm{T}$, Blons $\mathrm{H}$, Mabro M, Chibaudel B, Bachet JB, Tournigand C, Bennamoun M, Artru P, Nguyen S, Ebenezer C, Aissat N, Cayre A, Penault-Llorca F and Laurent-Puig P, de Gramont $A$ and GERCOR: Panitumumab combined with irinotecan for patients with KRAS wild-type metastatic colorectal cancer refractory to standard chemotherapy: a GERCOR efficacy, tolerance, and translational molecular study. Ann Oncol 24: 412-419, 2013.

10 Heidelberger C, Parsons DG and Remy DC: Syntheses of 5trifluoromethyluracil and 5-trifluoromethyl-2'-deoxyuridine. J Med Chem 7: 1-5, 1964.

11 Gottschling $\mathrm{H}$ and Heidelberger C: Fluorinated pyrimidines. XIX: Some biological effects of 5-trifluoromethyluracil and 5trifluoromethyl-2'-deoxyuridine on Escherichia coli and bacteriophage T4B: J Mol Biol 7: 541-560, 1963.

12 Heidelberger $\mathrm{C}$ and Anderson SW: Fluorinated pyrimidines. XXI: The tumor-inhibitory activity of 5-trifluoromethyl-2'deoxyuridine. Cancer Res 24: 1979-1985, 1964.
13 Yoshino T, Mizunuma N, Yamazaki K, Nishina T, Komatsu Y, Baba H, Tsuji A, Yamaguchi K, Muro K, Sugimoto N, Tsuji Y, Moriwaki T, Esaki T, Hamada C, Tanase T and Ohtsu A: TAS102 monotherapy for pretreated metastatic colorectal cancer: a double-blind, randomised, placebo-controlled phase 2 trial. Lancet Oncol 13: 993-1001, 2012.

14 Mayer RJ, Van Cutsem E, Falcone A, Yoshino T, GarciaCarbonero R, Mizunuma N, Yamazaki K, Shimada Y, Tabernero J, Komatsu Y, Sobrero A, Boucher E, Peeters M, Tran B, Lenz HJ, Zaniboni A, Hochster H, Cleary JM, Prenen H, Benedetti F, Mizuguchi H, Makris L, Ito M, Ohtsu A and RECOURSE Study Group: Randomized trial of TAS-102 for refractory metastatic colorectal cancer. N Engl J Med 372: 1909-1919, 2015.

15 Zaniboni A: New active drugs for the treatment of advanced colorectal cancer. World J Gastrointest Surg 7: 356-359, 2015.

16 Yoshino T, Uetake H, Fujita N, Furuta T, Katori J, Hara N and Muro K: TAS-102 safety in metastatic colorectal cancer: results from the first postmarketing surveillance study. Clin Colorectal Cancer 15: 205-211, 2016. 